\title{
PENINGKATAN KUALITAS PERMUKIMAN KUMUH UNTUK MENDUKUNG WISATA KAMPUNG PELANGI KOTA SEMARANG
}

\section{IMPROVEMENT OF THE QUALITY SETTLEMENT TO SUPPORT TOUR VILLAGE AT KAMPUNG PELANGI KOTA SEMARANG}

\author{
Anisa Riyulida ', S Sunarti ${ }^{1}$ \\ 'Departemen Perencanaan Wilayah dan Kota, Universitas Diponegoro Semarang, \\ Riyulidaa@ymail.com; n4rtio8@gmail.com
}

\section{Info Artikel:}

Artikel Masuk: 31 November 2018 Artikel diterima: 25 Februari $2019 \quad$ Tersedia Online: 31 Mei 2019

\begin{abstract}
ABSTRAK
Kampung Pelangi merupakan permukiman yang dipercantik melalui pengecatan sehingga menjadi Kampung wisata di Kota Semarang namun, masih terkesan kumuh. Hal ini menyebabkan permukiman belum layak huni bagi masyarakat. Oleh karena itu, dibutuhkan peningkatan kualitas permukiman untuk mengentaskan kumuh dan mendukung wisatanya. Penelitian ini bertujuan untuk mengkaji peningkatan kualitas permukiman yang dilakukan di Kampung Pelangi dalam pengembangan wisatanya. Metode analisis menggunakan pendekatan kuantitatif dengan teknik analisis deskriptif kuantitatif dan kualitatif. Hasil penelitian menunjukkan bahwa kegiatan peningkatan kualitas permukiman yang dilakukan adalah perbaikan rumah serta prasarana permukiman. Perbaikan yang paling siginifikan mengalami perubahan adalah atap rumah dan prasarana jalan. Dalam perbaikan ini, karakteristik sosial ekonomi masyarakat memiliki hubungan dengan kegiatan peningkatan kualitas permukiman yang dilakukan untuk mendukung wisata Kampung Pelangi. Hubungan yang paling lemah terdapat pada pendidikan masyarakat terhadap kegiatan perbaikan penghawaan rumahnya dengan nilai chi-square 0,046 dan nilai kontingen koefisiensi 0,303. Kondisi rumah ini perlu dilakukan perbaikan lebih lanjut dari segi perbaikan penghawaan rumah melalui pengembangan kapasitas masyarakat untuk mendukung obyek wisata di Kampung Pelangi. Dalam perbaikan prasarana permukiman, hubungan yang terbentuk bersifat cukup kuat pada status rumah masyarakat terhadap kegiatan pemeliharaan lingkungan di Kampung Pelangi dengan nilai chi-square 0,028 dan nilai kontingen koefisiensi 0,403. Pengembangan kapasitas masyarakat perlu ditingkatkan dalam hal kesadaran untuk memiliki rumah secara pribadi agar dapat berperan dalam perbaikan prasarana untuk mendukung fasilitas dan aksesibilitas wisata. Melalui pengembangan kapasitas ini akan menyebabkan masyarakat berperan dalam memelihara kualitas rumah dan prasarana permukimannya. Peningkatan kualitas permukiman dikembangkan untuk mendukung wisata Kampung Pelangi agar meningkatkan kualitas obyek wisata, memudahkan wisatawan yang berkunjung, dan dapat meningkatkan pendapatan masyarakat melalui aktivitas wisata.

Kata Kunci: Permukiman Kumuh; Kualitas Permukiman; Wisata;
\end{abstract}

\section{ABSTRACT}

Kampung Pelangi is a settlement that was beautified through painting so that it became a tourist village in the city of Semarang, however, it still seemed slum. This causes the settlements to be unfit for the community. Therefore, it is necessary to improve the quality of settlements to alleviate slums and support tourism. This study aims to examine the improvement of the quality of settlements carried out in Kampung Pelangi in its tourism development. The method of analysis uses a quantitative approach with quantitative and qualitative descriptive analysis techniques. The results showed that the settlement quality improvement activities carried out were home improvement and settlement infrastructure. The most significant improvements experienced were changes to the roof of the house and road infrastructure. In this improvement, the socio-economic characteristics of the community have a relationship with the quality improvement activities of the settlements carried out to support Kampung Pelangi tourism. The weakest relationship was found in public education on home improvement activities with a chi-square value of 0.046 and a contingent value of 0.303 coefficient. The condition of this house needs to be further improved in terms of improving house occupancy through developing community capacity to support tourism objects in Kampung Pelangi. In the improvement of settlement infrastructure, the relationship formed was strong enough on the status of the community's house on environmental maintenance activities in Kampung Pelangi with a chi-square value of 0.028 and a coefficient of coefficient of 0.403 . Community capacity building needs to be improved in terms of awareness of owning a home privately so that it can play a role in improving infrastructure to support tourism facilities and accessibility. Through the development of this capacity, it will cause the community to play a role in maintaining the quality of their housing and infrastructure. Improving the quality of settlements was developed to support Kampung Pelangi tourism in order to improve the quality of tourism objects, make it easier for tourists to visit, and can increase people's income through tourism activities.

Keyword: Slum; Quality Of Settlement; Tourism; 


\section{PENDAHULUAN}

Kurangnya perencanaan kota dan kebijakan permukiman telah menyebabkan penciptaan permukiman kumuh di daerah perkotaan (Uddin, 2018). Kawasan kumuh tersebut menyebabkan batasan ruang huni yang ditempati masyarakat Indonesia masih kurang memadai, kurang nyaman dan berdampak buruk pada lingkungan permukimannya.

Permukiman kumuh pada dasarnya memiliki kondisi perumahan yang dibawah standar dengan kepadatan tinggi dan tidak sehat. Permukiman kumuh ini dapat ditangani melalui penyadaran masyarakat melalui program pemerintah, LSM, dan sektor swasta (Uddin, 2018). Selain itu, Permukiman kumuh ini dapat diarahkan berdasarkan peningkatan kualitas rumah sehat, kualitas prasarana sanitasi, air bersih, drainase, daya dukung lingkungan dan pemberdayaan masyarakat (Muhammad B.A \& Sulistyarso, 2016). Hal ini senada dengan yang dijelaskan oleh Moitra (1991), bahwa perlunya pendekatan praktis untuk meningkatkan kualitas hidup di permukiman kumuh telah menghasilkan peningkatan yang lambat namun sangat signifikan yang dapat diukur secara kuantitatif melalui peningkatan kualitas permukiman. Oleh karena itu, dalam penanganan masalah permukiman kumuh diperlukan adanya peningkatan kualitas permukiman.

Kampung Pelangi merupakan suatu kawasan yang teridentifikasi sebagai kawasan kumuh. Hal ini karena Kampung ini memiliki kepadatan penduduk yang tinggi sebesar 566 jiwa/Ha. Kegiatan peningkatan kualitas permukiman yang dilakukan di kawasan ini seperti membentuk suatu kawasan permukiman dengan rumah dan prasarana yang diperbaiki dan dicat berwarna warni sehingga berpotensi menjadi wisata kampung pelangi. Potensi wisata ini perlu dikembangkan sebagai bentuk dari pengembangan yang dapat memungkinkan orang luar melihat menjadi terinsipasi, dan diperkaya dengan sedikit pemahaman tentang perlunya sebuah perubahan (Nisbett, 2017). Adanya potensi wisata ini, akan membuat masyarakat sadar akan perubahan yang ada di lingkungan mereka. Hal ini akan membantu masyarakat meningkatkan kualitas hidup dan permukimannya. Hal ini yang mendorong perlunya penelitian ini karena selain membahas mengenai peningkatan kualitas permukiman kumuh, namun bagaimana peningkatan kualitas permukiman ini berperan untuk mendukung pengembangan wisata Kampung Pelangi. Penelitian ini bertujuan untuk mengkaji kegiatan peningkatan kualitas permukiman kumuh untuk menunjang keberlanjutan wisata Kampung Pelangi.

\section{DATA DAN METODE}

Pendekatan penelitian yang digunakan adalah kuantitatif. Hueso dan Cascant (2012 dalam (Suárez, dkk, 2017) menjelaskan bahwa, pada dasarnya penelitian kuantitatif merupakan penggunaan teknik statistik untuk mengetahui aspek-aspek tertentu yang menarik pada populasi atau sampel yang diteliti. Melalui penelitian kuantitatif ini, akan didapatkan gambaran deskripsi fenomena dan pengaruh dari variabel penelitian secara sistematis.

Data yang digunakan dalam penelitian ini meliputi data kuantitatif dan kualitatif. Data kuantitatif seperti karakteristik sosial ekonomi masyarakat, dan kondisi fisik permukiman masyarakat. Data kualitatif berupa pengembangan aspek wisata di Kampung Pelangi. Pengumpulan data berupa memberikan kuesioner pada masyarakat, observasi di lapangan, dan wawancara dengan stakeholder yang terlibat dalam peningkatan kualitas permukiman Kampung Pelangi.

Jumlah responden yang digunakan dalam penelitian ini yaitu sejumlah 96 orang yang tersebar di RW 3 dan 4 Kampung Pelangi Kelurahan Randusari Kota Semarang. Sampel responden penelitian diperoleh melalui cara accidental sampling. Sampel ini adalah tiap orang dari masyarakat RW 3 dan 4 yang ditemui pada saat observasi di Kampung Pelangi.

Teknik analisis yang digunakan yakni deskriptif kuantitatif dan kualitatif untuk menyatakan perubahan peningkatan kualitas permukiman untuk mendukung wisata Kampung pelangi. Deskriptif kuantitatif menggunakan alat analisis chi-square dan kontingensi koefisiensi. Chi-square digunakan untuk menganalisis hubungan yang terbentuk antara karakteristik masyarakat terhadap kegiatan peningkatan kualitas permukiman. Kontingen koefisiensi untuk menyatakan 
arah lemah dan kuatnya hubungan yang terbentuk antara karakteristik sosial ekonomi masyarakat terhadap kegiatan peningkatan kualitas permukiman.

Dalam analisis chi-square terdapat taraf signifikansi $5 \%$ dengan ketentuan jika nilai chi-square $<5 \%(0,05)$, maka artinya terdapat hubungan. Jika nilai chi-square $>5 \%(0,05)$, maka tidak terdapat hubungan (Riduwan dan Sunarto, 2014). Kaidah interpretasi nilai koefisien kontingensi (C) adalah semakin mendekati angka 1 semakin kuat hubungan tersebut. Selain itu, analisis deskriptif kualitatif digunakan untuk mengkaji peningkatan kualitas permukiman yang dilakukan untuk mendukung wisata Kampung Pelangi dan akan menjawab tujuan penelitian.

\section{HASIL DAN PEMBAHASAN}

\subsection{Gambaran Umum}

Secara geografis, Kampung Pelangi berada di Kelurahan Randusari dalam wilayah administrasi Kecamatan Semarang Selatan Kota Semarang. Kelurahan Randusari memiliki luas wilayah $66.95 \mathrm{Ha} \mathrm{km}^{2}$ dengan batas sebelah utara dan selatan berbatasan dengan Kecamatan Semarang Tengah, dan Kecamatan Gajahmungkur. Sementara itu, sebelah timur dan barat berbatasan dengan kelurahan Barusari dan Mugasari (Laporan Monografi Kelurahan Randusari, 2018).

Kampung Pelangi terdiri dari Rukun Warga (RW) 3 dan 4 yang terletak di Kelurahan Randusari, Kecamatan Semarang Selatan, Kota Semarang. Total luas kawasan ini sekitar \pm 4 Ha. (Dinas Penataan Ruang Kota Semarang,2018). Kawasan Kampung Pelangi ini dapat dilihat dalam gambar 1 berikut ini.

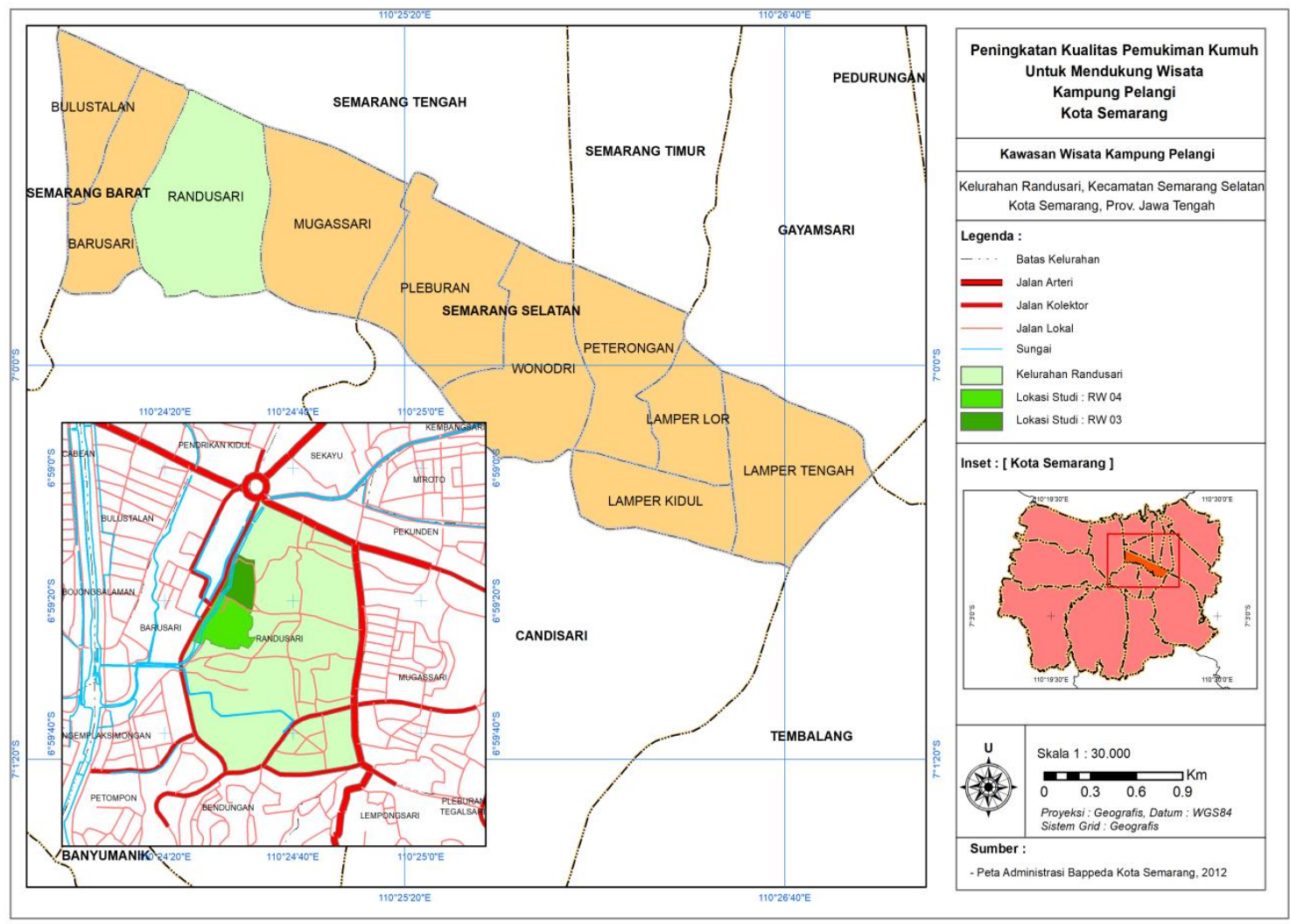

Sumber: Hasil Analisis 2019

Gambar 1. Peta Lokasi Penelitian

Jumlah penduduk di kawasan ini adalah 2.266 jiwa yang terdiri dari 1.405 jiwa di kawasan RW 3 dan 861 jiwa di kawasan RW 4. Jumlah penduduk yang mendominasi di Kampung Pelangi 
RW 3 berusia 0-15 tahun. Jumlah penduduk di RW 4 didominasi oleh penduduk yang berusia 36 61 tahun keatas. Hal ini berarti sebagian besar penduduk di RW 3 Kampung Pelangi berada pada usia muda dan wilayah RW 4 di Kampung Pelangi terdiri dari masyarakat dengan usia produktif. Berdasarkan tingkat pendidikan, penduduk di kawasan Kampung Pelangi didominasi oleh lulusan SMA yang bekerja sebagai pegawai swasta (Dinas Penataan Ruang Kota Semarang,2018).

Jumlah total rumah yang dicat sebanyak kurang lebih 391 unit rumah di RW 3 dan 4. Permukiman di Kampung Pelangi berkembang secara alami menyesuaikan kondisi topografi. Lokasi dan letak rumah membentuk pola terasiring dari tepi sungai kali Semarang ke arah timur. Arah ini mengikuti kontur sampai dengan makam Bergota sehingga menyebabkan adanya pemandangan warna warni rumah di Kampung Pelangi (Dinas Penataan Ruang Kota Semarang,2018).

Kondisi jalan Kampung Pelangi menyesuaikan kelerengan tanah. Hal ini menyebabkan sebagian besar jalan dibentuk seperti tangga untuk memudahkan warga dalam melakukan kegiatan sehari-hari. Jalan utama pada tiap-tiap gang dihubungkan dengan jembatan ke jalan Dr. Sutomo. Perkerasan masing-masing jalan berbeda ada yang aspal, paving, ataupun plesteran. Drainase di Kampung Pelangi juga mengikuti kelerengan jalan sehingga senantiasa mengalirkan air tanpa menyebabkan genangan. (Dinas Penataan Ruang Kota Semarang,2018).

\subsection{Karakteristik Sosial Ekonomi Masyarakat Kampung Pelangi}

Berdasarkan data yang diperoleh melalui penyebaran kuesioner kepada responden penelitian, maka didapatkan kondisi sosial ekonomi masyarakat Kampung Pelangi yang dapat dilihat dalam tabel 1 berikut ini.

Tabel 1. Karakteristik Sosial Ekonomi Masyarakat Kampung Pelangi

\begin{tabular}{|c|c|c|c|}
\hline VARIABEL & KRITERIA VARIABEL & FREKUENSI & PERSENTASE \\
\hline & Tidak Sekolah & 1 & $1 \%$ \\
\hline & SD & 7 & $7 \%$ \\
\hline \multirow[t]{3}{*}{ Pendidikan } & SMP & 29 & $30 \%$ \\
\hline & SMA & 54 & $56 \%$ \\
\hline & $\mathrm{D} 1-\mathrm{S} 1$ & 5 & $5 \%$ \\
\hline \multirow[t]{3}{*}{ TOTAL } & & 96 & $100 \%$ \\
\hline & Pedagang Bunga & 17 & $18 \%$ \\
\hline & Wiraswasta & 24 & $25 \%$ \\
\hline \multirow[t]{4}{*}{ Pekerjaan } & Swasta & 38 & $40 \%$ \\
\hline & Pegawai Negeri & 1 & $1 \%$ \\
\hline & Pensiun & 3 & $3 \%$ \\
\hline & Tidak Bekerja & 13 & $13 \%$ \\
\hline \multirow[t]{3}{*}{ TOTAL } & & 96 & $100 \%$ \\
\hline & $<$ Rp.500.000 & 16 & $17 \%$ \\
\hline & Rp.500.000 - Rp.1.500.000 & 21 & $22 \%$ \\
\hline \multirow[t]{4}{*}{ Penghasilan } & Rp.1.600.000 - Rp.2.500.000 & 36 & $38 \%$ \\
\hline & Rp.2.600.000 - Rp.3.500.000 & 6 & $6 \%$ \\
\hline & $>$ Rp.3.500.000 & 4 & $4 \%$ \\
\hline & Tidak Ada & 13 & $13 \%$ \\
\hline \multirow[t]{2}{*}{ TOTAL } & & 96 & $100 \%$ \\
\hline & Pribadi & 51 & $53 \%$ \\
\hline Status & Sewa/Kontrak & 3 & $3 \%$ \\
\hline Kepemilikan & Milik Orang Tua & 41 & $43 \%$ \\
\hline Rumah & Lainnya & 1 & $1 \%$ \\
\hline TOTAL & & 96 & $100 \%$ \\
\hline
\end{tabular}

Sumber: Hasil Analisis 2019

Kondisi pendidikan masyarakat paling banyak berpendidikan terakhir setingkat SMA dengan persentase sebanyak $56 \%$. Hal ini cukup mendasari bahwa masyarakat sudah sadar akan 
pentingnya pendidikan. Pendidikan merupakan pondasi utama dalam proses kehidupan untuk pengembangan pengalaman. Hal ini memungkinkan individu mengelola lingkungan dengan baik, dan dapat bertanggung jawab (Khan, 2014). Oleh karena itu, melalui kesadaran masyarakat akan pendidikan di Kampung Pelangi, masyarakat sudah bertanggung jawab dalam pengelolaan lingkungan permukimannya sehingga menjadi lebih baik.

Sebagian besar masyarakat Kampung Pelangi memiliki penghasilan sebesar Rp.1.600.000 hingga Rp.2.500.000 dengan persentase sebanyak 38\%. Secara kehidupan ekonomi, masyarakat Kampung Pelangi masih tergolong MBR (Masyarakat Berpenghasilan Rendah) menurut PermenPU No. 05/PRT/M/2007. Hal ini mengartikan bahwa tingkat pendidikan dan pekerjaan masyarakatnya masih rendah.

Masyarakat sudah menempati rumah dengan status hak milik pribadi dengan persentase sebanyak 53\%. Rasa kepemilikan untuk status rumah masyarakat menyebabkan keterikatan manusia dengan lingkungannya (Ghoomi, dkk, 2015). Hal tersebut sangat penting dalam peningkatan kualitas permukiman karena masyarakat mempunyai akses dan keterikatan untuk memperbaiki rumah dan mengelola lingkungan permukiman mereka.

\subsection{Perubahan Kondisi Fisik Permukiman Kampung Pelangi dalam Peningkatan Kualitas Permukiman Untuk Mendukung Wisata}

Kondisi fisik permukiman ini dilakukan untuk melihat kualitas perumahan dan prasarana lingkungan yang ditinggali oleh masyarakat di Kampung Pelangi pada saat sebelum dan sesudah kawasan ini ditetapkan menjadi kawasan kampung wisata. Dalam peningkatan kualitas rumah masyarakat Kampung Pelangi, kriteria yang dilihat kondisi atap, dinding, lantai, penghawaan rumah, dan sanitasi rumah. Pada peningkatan kualitas prasarana permukiman Kampung Pelangi kriteria yang dilihat perubahannya adalah pada kondisi jalan, drainase, dan persampahan.

Berdasarkan kriteria penilaian kondisi fisik rumah dan permukiman di Kampung Pelangi yang telah ditentukan, maka didapatkan perubahan kondisi fisik permukiman Kampung Pelangi. Kondisi ini merepresentatifkan perubahan/peningkatan ketika sebelum dan sesudah menjadi kampung wisata seperti tabel 2 berikut ini.

Tabel 2. Kondisi Fisik Rumah dan Prasarana Masyarakat di Kawasan Kampung Pelangi Sebelum dan Sesudah Menjadi Kawasan Wisata

\begin{tabular}{|c|c|c|c|c|c|c|}
\hline \multirow[t]{2}{*}{ Variabel } & \multirow{2}{*}{$\begin{array}{l}\text { Kriteria } \\
\text { Kondisi }\end{array}$} & \multicolumn{2}{|c|}{ SEBELUM } & \multicolumn{2}{|c|}{ SESUDAH } & \multirow{2}{*}{$\begin{array}{c}\text { Selisih } \\
\text { Perubahan }\end{array}$} \\
\hline & & Frekuensi & Persentase & Frekuensi & Persentase & \\
\hline & $\begin{array}{l}\text { Genteng tidak } \\
\text { bocor dengan } \\
\text { plafon }\end{array}$ & 34 & $35 \%$ & 45 & $47 \%$ & $12 \%$ \\
\hline \multirow[t]{3}{*}{$\begin{array}{l}\text { Atap } \\
\text { Rumah }\end{array}$} & $\begin{array}{c}\text { Genteng tidak } \\
\text { bocor tanpa plafon }\end{array}$ & 15 & $16 \%$ & 23 & $25 \%$ & $9 \%$ \\
\hline & $\begin{array}{l}\text { Genteng sesekali } \\
\text { bocor dengan } \\
\text { plafon }\end{array}$ & 37 & $39 \%$ & 18 & $19 \%$ & $20 \%$ \\
\hline & $\begin{array}{l}\text { Genteng bocor } \\
\text { tanpa plafon }\end{array}$ & 10 & $10 \%$ & 9 & $9 \%$ & - \\
\hline \multirow[t]{2}{*}{ Total } & & 96 & $100 \%$ & 96 & $100 \%$ & - \\
\hline & Beton permanen & 26 & $27 \%$ & 26 & $27 \%$ & - \\
\hline \multirow[t]{3}{*}{ Dinding Rumah } & Batubata & 63 & $66 \%$ & 63 & $66 \%$ & - \\
\hline & Kayu/Bambu & 7 & $7 \%$ & 7 & $7 \%$ & - \\
\hline & Botol Kaca & 0 & $0 \%$ & 0 & $0 \%$ & - \\
\hline \multirow[t]{2}{*}{ Total } & & 96 & $100 \%$ & 96 & $100 \%$ & - \\
\hline & Keramik & 17 & $18 \%$ & 17 & $18 \%$ & - \\
\hline Lantai & Semen & 73 & $76 \%$ & 73 & $76 \%$ & - \\
\hline \multirow[t]{2}{*}{ Rumah } & Kayu & 2 & $2 \%$ & 2 & $2 \%$ & - \\
\hline & Tanah & 4 & $4 \%$ & 4 & $4 \%$ & - \\
\hline
\end{tabular}


Riyulida, Sunarti/ Jurnal Pembangunan Wilayah dan Kota, Vol 15, No. 2, 2019, 83-95 Doi: https://doi.org/10.14710/pwk.v15i2.21270

\begin{tabular}{|c|c|c|c|c|c|c|}
\hline \multirow[t]{2}{*}{ Variabel } & \multirow{2}{*}{$\begin{array}{l}\text { Kriteria } \\
\text { Kondisi }\end{array}$} & \multicolumn{2}{|c|}{ SEBELUM } & \multicolumn{2}{|c|}{ SESUDAH } & \multirow{2}{*}{$\begin{array}{c}\text { Selisih } \\
\text { Perubahan }\end{array}$} \\
\hline & & Frekuensi & Persentase & Frekuensi & Persentase & \\
\hline Total & & 96 & $100 \%$ & 96 & $100 \%$ & - \\
\hline Penghawaan & $\begin{array}{l}\text { Pintu, jendela, dan } \\
\text { lubang angin }\end{array}$ & 77 & $80 \%$ & 80 & $83 \%$ & $3 \%$ \\
\hline \multirow[t]{3}{*}{ Rumah } & Pintu dan jendela & 19 & $20 \%$ & 16 & $17 \%$ & $3 \%$ \\
\hline & Pintu saja & 0 & 0 & 0 & 0 & - \\
\hline & Tidak ada pintu & 0 & 0 & 0 & 0 & - \\
\hline \multirow[t]{2}{*}{ Total } & & 96 & $100 \%$ & 96 & $100 \%$ & - \\
\hline & $\begin{array}{c}\text { Ada kamar mandi } \\
\text { dan WC }\end{array}$ & 86 & $90 \%$ & 86 & $90 \%$ & - \\
\hline \multirow[t]{3}{*}{ Sanitasi Rumah } & $\begin{array}{l}\text { Ada kamar mandi } \\
\text { tidak ada WC }\end{array}$ & 0 & 0 & 1 & $1 \%$ & $1 \%$ \\
\hline & $\begin{array}{l}\text { Kamar mandi dan } \\
\text { WC diluar rumah }\end{array}$ & 10 & $10 \%$ & 9 & $9 \%$ & $1 \%$ \\
\hline & $\begin{array}{l}\text { Tidak ada kamar } \\
\text { mandi dan WC }\end{array}$ & 0 & 0 & 0 & 0 & - \\
\hline \multirow[t]{3}{*}{ Total } & & 96 & $100 \%$ & 96 & $100 \%$ & - \\
\hline & Aspal & 3 & $25 \%$ & 6 & $50 \%$ & $25 \%$ \\
\hline & Paving & 8 & $67 \%$ & 6 & $50 \%$ & $17 \%$ \\
\hline \multirow[t]{2}{*}{ Jalan } & Paving Rusak & 1 & $8 \%$ & 0 & 0 & $8 \%$ \\
\hline & Tanah & 0 & 0 & 0 & 0 & - \\
\hline \multirow[t]{3}{*}{ Total } & & 12 & $100 \%$ & 12 & $100 \%$ & - \\
\hline & $\begin{array}{l}\text { Saluran besar dan } \\
\text { lancar }\end{array}$ & 1 & $8 \%$ & 3 & $25 \%$ & $17 \%$ \\
\hline & $\begin{array}{c}\text { Saluran besar } \\
\text { kadang tersumbat }\end{array}$ & 2 & $17 \%$ & 1 & $8 \%$ & $9 \%$ \\
\hline \multirow[t]{2}{*}{ Drainase } & $\begin{array}{c}\text { Saluran kecil dan } \\
\text { lancar }\end{array}$ & 7 & $58 \%$ & 7 & $58 \%$ & - \\
\hline & $\begin{array}{c}\text { Saluran kecil } \\
\text { kadang tersumbat }\end{array}$ & 2 & $17 \%$ & 1 & $8 \%$ & $9 \%$ \\
\hline \multirow[t]{2}{*}{ Total } & & 12 & $100 \%$ & 12 & $100 \%$ & - \\
\hline & $\begin{array}{l}\text { Ada pemisahan } \\
\text { tempat sampah }\end{array}$ & 1 & $8 \%$ & 3 & $25 \%$ & $17 \%$ \\
\hline \multirow[t]{3}{*}{$\begin{array}{l}\text { Persampahan } \\
\text { Lingkungan }\end{array}$} & $\begin{array}{c}\text { Ada tempat } \\
\text { sampah tanpa } \\
\text { pemisahan }\end{array}$ & 10 & $83 \%$ & 9 & $75 \%$ & $8 \%$ \\
\hline & $\begin{array}{c}\text { Tidak ada tempat } \\
\text { sampah }\end{array}$ & 1 & $8 \%$ & 0 & 0 & $8 \%$ \\
\hline & $\begin{array}{c}\text { Sampah dibuang ke } \\
\text { sungai }\end{array}$ & 0 & 0 & 0 & 0 & - \\
\hline Total & & 12 & $100 \%$ & 12 & $100 \%$ & - \\
\hline
\end{tabular}

Sumber: Hasil Analisis 2019

Dalam peningkatan kualitas rumah, perbaikan yang paling banyak dilakukan adalah atap rumah masyarakat. Perubahan atap rumah ini, sebelumnya pada kondisi bocor, menjadi tidak bocor dengan plafon. Perubahan ini memiliki selisih persentasi paling banyak sebesar $20 \%$. Dalam peningkatan kualitas prasarana permukiman, perubahan signifikan terlihat pada kondisi jalan berbahan paving menjadi aspal dengan selisih perubahan sebesar $25 \%$. Dinding dan lantai rumah masyarakat tidak mengalami perubahan.

Perubahan ini menjadi gambaran bahwa permukiman Kampung Pelangi mengalami peningkatan hanya tampak luar kondisi rumah dan prasarana permukiman yang menunjang kebutuhan masyarakat. Klasifikasi kebutuhan manusia menurut Maslow (1970 dalam (Javad, Poor, \& Jusan, 2012) terdiri dari lima tingkat kebutuhan kognitif, termasuk kebutuhan fisiologis, kebutuhan aman dan nyaman, kebutuhan rasa memiliki dan cinta, kebutuhan penghargaan, dan 
kebutuhan untuk aktualisasi diri. Perbaikan permukiman Kampung Pelangi yang dilakukan masyarakat, ditujukan untuk memenuhi kebutuhan masyarakat secara individu pada level fisiologis dan keselamatannya. Hal ini karena perbaikan rumah yang dilakukan masyarakat untuk memenuhi kebutuhan dasar dalam memiliki tempat tinggal untuk berteduh bersama keluarga. Perbaikan prasarana jalan dilakukan masyarakat bersama-sama agar memiliki akses yang mudah dan merasa nyaman dalam melakukan mobilitas/aktivitas sehari-hari.

\subsection{Pengembangan Aspek Wisata Kampung Pelangi}

Analisis ini ditujukan untuk melihat unsur pengembangan wisata Kampung Pelangi yang perlu diperhatikan. Aspek wisata ini diantaranya adalah obyek wisata, fasilitas pelayanan wisata, aksesibilitas wisata, dan pemasaran wisata (Yoeti,2003).

\subsubsection{Pengembangan Obyek dan Fasilitas Pelayanan Wisata di Kampung Pelangi}

Obyek wisata Kampung Pelangi berupa rumah warga yang dicat berwarna warni. Obyek wisata di Kampung Pelangi yang paling digemari masyarakat secara umum adalah photo selfie. Untuk menunjang obyek wisata ini masyarakat melakukan perbaikan rumah, mengecat ulang rumahnya, dan melakukan pemeliharaan sungai. Perbaikan rumah dilakukan hanya untuk berteduh sehingga belum memenuhi kebutuhan masyarakat akan aktualisasinya dan belum bisa mendukung adanya kampung wisata (Sunarti, Rahdriawan, Dewi, \& Widiarta, 2018). Hal ini menyebabkan perbaikan rumah belum berperan maksimal dalam mendukung obyek wisata Kampung Pelangi. Perbaikan rumah ini dilakukan masyarakat secara swadaya. Dalam pemeliharaan prasarana untuk mendukung adanya suatu Kampung obyek wisata, kegiatan yang dilakukan adalah pembersihan sungai. Oleh karena itu, keberadaan sungai perlu dilestarikan dan dikembangkan. Hal ini karena sungai sering dijadikan lokasi event wisata seperti pemancingan massal sehingga perlu kegiatan pemeliharaan sungai agar selalu bersih.

Menurut Wiggins dan Croston (2011 dalam (Pantano, dkk, 2017), menjelaskan bahwa suatu tujuan wisata harus mengembangkan obyek wisata seperti, pemandangan budaya, transportasi, pemasaran, dan lingkungan wisata. Dalam wisata Kampung Pelangi, obyek wisata yang ditawarkan adalah pemandangan budaya, dan lingkungan wisata. Kualitas wisata diukur dari obyek wisatanya (Changbo \& Jingjing, 2011). Oleh karena itu, perlu adanya pengembangan lebih lanjut untuk rumah dan prasarana wisata Kampung Pelangi dalam meningkatkan kualitas wisata Kampung Pelangi.

Fasilitas pelayanan wisata di Kampung Pelangi, hanya terdapat taman lingkungan yakni taman kasmaran untuk fasillitas wisatawan dan masyarakat sekitar. Kawasan wisata Kampung Pelangi belum mampu memberikan fasilitas Akomodasi bagi wisatawan. Hal ini karena kawasan ini hanya merupakan wisata Kampung yang dihuni masyarakat dengan obyek wisata foto-foto. Oleh karena itu, perlu pengembangan lebih lanjut untuk fasilitas akomodasi wisata Kampung Pelangi seperti adanya homestay dan tourguide. Pengembangan obyek dan fasilitas wisata yang dilakukan di Kampung Pelangi dapat dilihat pada gambar 2.

\subsubsection{Pengembangan Aksesibilitas dan Pemasaran Wisata di Kampung Pelangi}

Aksesibilitas wisatawan menuju Kampung Pelangi dapat terjangkau secara mudah. Hal ini karena lokasi wisata yang dekat dengan pusat kota Semarang yakni Tugu Muda dan simpang lima di Jalan Pandanaran. Kampung Pelangi merupakan salah satu lokasi wisata yang dikunjungi bus Si Kenang Wisata Kota Semarang. Rute bus Si Kenang Wisata ini dimulai dari Museum Mandala Bakhti menuju Tugu Muda di Jl. Imam Bonjol, kemudian menuju Kota Lama, Simpang Lima dan jalan Dr. Sutomo berhenti di Kampung Pelangi. Selain itu, Transportasi untuk menuju Kampung Pelangi bisa bisa ditempuh melalui alat transportasi apa saja seperti mobil, motor, dll. Wisata harus memudahkan aksesibilitas semua orang, terutama yang ramah lingkungan dan menarik banyak wisatawan (Jamaludin \& Abdul, 2012). Dengan adanya transportasi ini memudahkan wisatawan yang berkunjung menuju lokasi wisata. Terdapat kekurangan dalam aksesibilitas transportasi wisata Kampung Pelangi, yakni belum adanya lahan parkir yang luas dan memadai 
Riyulida, Sunarti/ Jurnal Pembangunan Wilayah dan Kota, Vol 15, No. 2, 2019, 83-95 Doi: https://doi.org/10.14710/pwk.v15i2.21270

bagi wisatawan yang datang menggunakan alat transportasi pribadi. Hal ini harus menjadi pengembangan lebih lanjut.

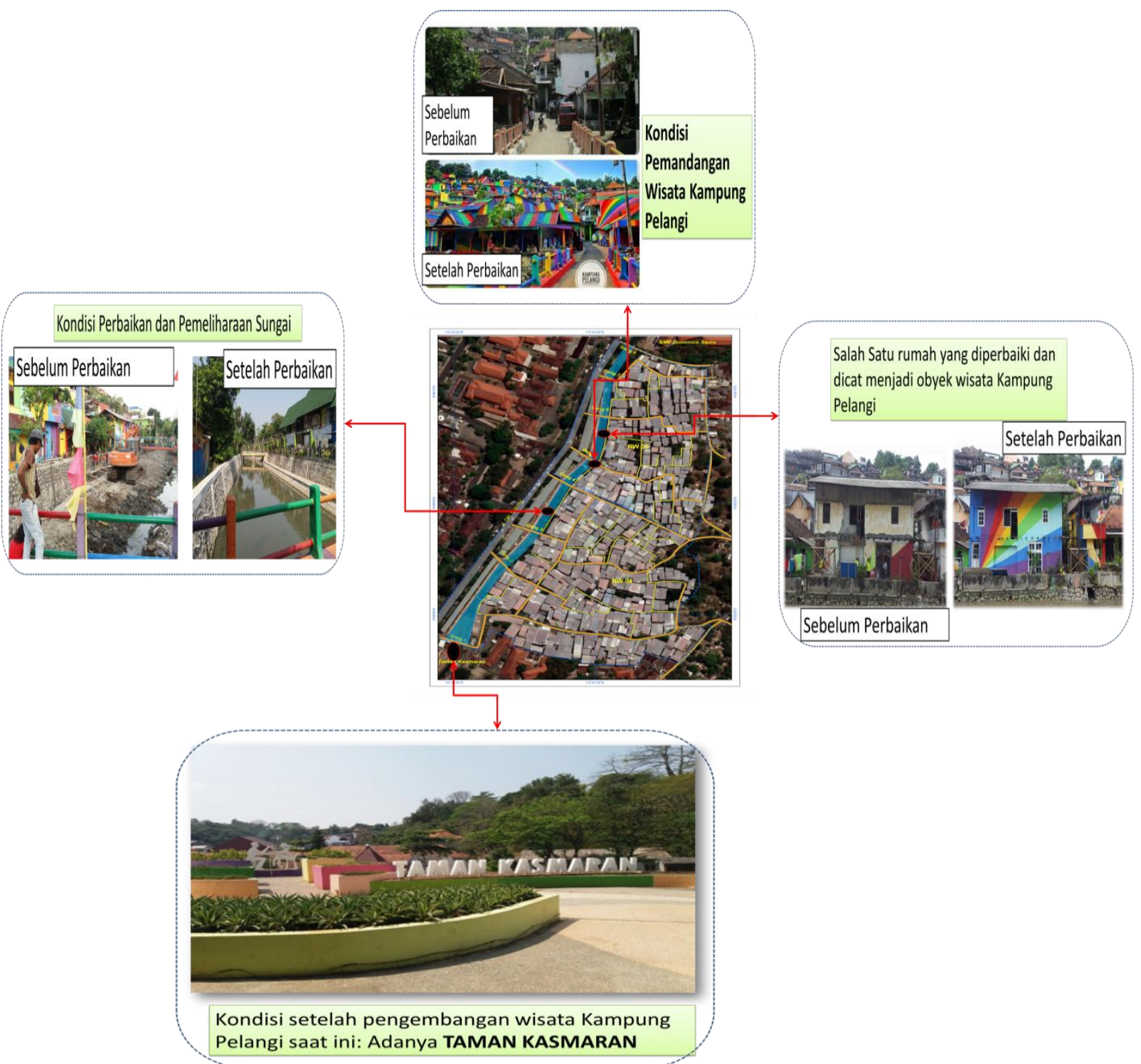

Sumber: Hasil Analisis, 2019

Gambar 2. Pengembangan Obyek dan Fasilitas Wisata Kampung Pelangi

Peningkatan kualitas prasarana permukiman untuk mendukung aksesibilitas wisata di Kampung Pelangi seperti; perbaikan jalan, adanya MCK umum dan penunjuk jalan di wisata Kampung Pelangi. Hal ini diindikasikan dengan adanya kegiatan pengecatan jalan, dan pembersihan jalan. MCK umum dan penunjuk jalan ditujukan untuk memudahkan wisatawan dalam mengelilingi area wisata Kampung Pelangi. Perbaikan prasarana dilakukan dengan bantuan dari pemerintah.

Dalam proses pemasaran wisata Kampung Pelangi, pihak yang terkait dalam pemasaran wisata Kampung Pelangi ini dilakukan oleh kelompok sadar wisata dari Kampung Pelangi dan juga pemerintah Kota Semarang. Langkah tahapan pemasarannya terdiri dari branding, advertising, dan selling. Pemasaran wisata memiliki strategi yang berdampak pada pembangunan sosial daerah wisata (Jeuring, 2016). Hal ini akan meningkatkan kualitas wisata dan taraf hidup masyarakat di KampungPelangi. 
Promosi wisata dilakukan melalui media visual seperti TV, online internet, dan cetak. Suasana Kampung Pelangi pernah ditayangkan dalam TV swasta RCTI dalam serial Tukang Ojek Pengkolan. Hal ini menjadi media pemasaran wisata Kampung Pelangi secara visual oleh media televisi. Media online internet yang digunakan seperti sosial media yang digunakan untuk memasarkan seperti Facebook, Instagram, dan Website. Media cetak yang digunakan yakni brosur dan surat kabar yang memuat tentang Kampung Pelangi. Dalam hal ini, tidak ada kegiatan peningkatan kualitas permukiman yang mendukung pemasaran wisata Kampung Pelangi.

Pengembangan Aksesibilitas wisata yang dilakukan di Kampung Pelangi dapat dilihat pada gambar 3 berikut.

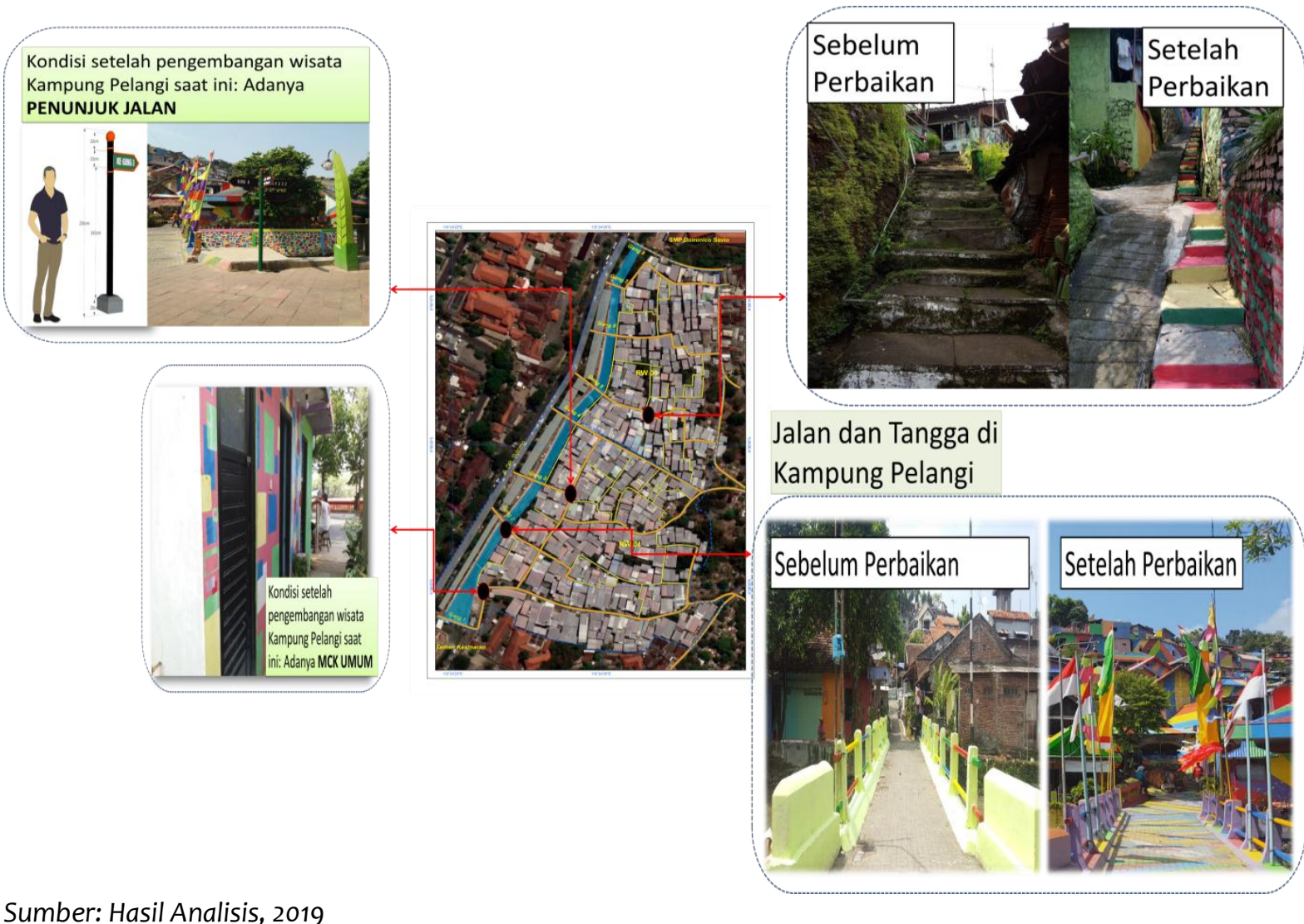

Gambar 3. Pengembangan Aksesibilitas Wisata Kampung Pelangi

\subsection{Hubungan Karakteristik Sosial Ekonomi Masyarakat Terhadap Peningkatan Kualitas Rumah dan Prasarana Permukiman untuk Mendukung Wisata Kampung Pelangi}

Analisis ini bertujuan untuk melihat hubungan antara karakteristik sosial ekonomi masyarakat terhadap perbaikan rumah dan perbaikan prasarana permukiman di Kampung Pelangi. Sebelum masuk pada teknik analisis terlebih dahulu ditentukan variabel bebas (independen) dan terikatnya (dependen). Variabel bebas dalam hal ini adalah karakteristik sosial ekonomi masyarakat dan variabel terikat adalah kegiatan masyarakat dalam peningkatan kualitas permukiman.

Karakteristik sosial ekonomi yang digunakan adalah pendidikan, status kepemilikan rumah masyarakat, pekerjaan, dan penghasilan masyarakat Kampung Pelangi. Kegiatan perbaikan rumah yang diteliti hubungannya dengan karakteristik sosial ekonomi adalah perbaikan atap, perbaikan penghawaan rumah, dan perbaikan sanitasi rumah.

Kegiatan perbaikan prasarana yang diteliti dalam hubungannya dengan karakteristik sosial ekonomi adalah perbaikan jalan, perbaikan drainase, dan pemeliharaan lingkungan. Dinding dan 
Riyulida, Sunarti/ Jurnal Pembangunan Wilayah dan Kota, Vol 15, No. 2, 2019, 83-95 Doi: https://doi.org/10.14710/pwk.v15i2.21270

lantai tidak menjadi variabel dalam analisis ini karena tidak mengalami perubahan fisik sejak menjadi wisata Kampung Pelangi. Hubungan karakteristik sosial ekonomi masyarakat terhadap perbaikan rumah dapat dilihat dalam tabel 3 berikut ini.

Tabel 3. Nilai Chi-Square Dalam Hubungan Karakteristik Sosial Ekonomi Masyarakat Terhadap Kondisi Rumah

\begin{tabular}{|c|c|c|c|c|c|c|}
\hline \multirow[t]{2}{*}{$\begin{array}{c}\text { Karakteristik Sosial } \\
\text { Ekonomi }\end{array}$} & \multicolumn{2}{|c|}{$\begin{array}{l}\text { Perbaikan Atap } \\
\text { Rumah }\end{array}$} & \multicolumn{2}{|c|}{$\begin{array}{c}\text { Perbaikan } \\
\text { Penghawaan Rumah }\end{array}$} & \multicolumn{2}{|c|}{$\begin{array}{c}\text { Perbaikan Sanitasi } \\
\text { Rumah }\end{array}$} \\
\hline & $X^{2}$ & C & $X^{2}$ & C & $\mathrm{X}^{2}$ & C \\
\hline PENDIDIKAN & 0,004 & 0,480 & 0,046 & 0,303 & 0,085 & 0,355 \\
\hline PEKERJAAN & 0,039 & 0,461 & 0,169 & 0,274 & 0,669 & 0,271 \\
\hline PENGHASILAN & 0,010 & 0,492 & 0,192 & 0,268 & 0,502 & 0,298 \\
\hline $\begin{array}{l}\text { STATUS RUMAH } \\
\text { KET. }\end{array}$ & 0,004 & 0,451 & 0,001 & 0,374 & 0,009 & 0,389 \\
\hline$X^{2}=$ Nilai Chi-Square, & $\mathrm{C}=$ Nilai & ntingen & Koefiensi & & & \\
\hline
\end{tabular}

Hubungan yang cukup kuat terdapat pada penghasilan masyarakat terhadap kegiatan perbaikan atap rumahnya dengan nilai chi-square 0.010 dan nilai kontingen koefisiensi 0.492 . Masyarakat akan memenuhi standar kualitas rumah yang layak huni ketika memiliki dana/materi yang sesuai untuk (Kurnianingrum, 2016). Hal ini menyebabkan semakin baik penghasilan yang didapatkan masyarakat melalui pekerjaannya, maka semakin mampu dalam memperbaiki dan meningkatkan kualitas rumah pribadi mereka di Kampung Pelangi. Kualitas rumah yang rendah diakibatkan oleh ekonomi masyarakat yang rendah (Spirkova, dkk, 2017). Oleh karena itu, penghasilan masyarakat perlu ditingkatkan agar kualitas rumah meningkat.

Hubungan yang paling rendah terdapat pada pendidikan masyarakat terhadap perbaikan penghawaan rumahnya dengan nilai chi-square 0.046 dan nilai kontingen koefisiensi 0.303 . Pendidikan masyarakat terhadap penghawaan rumahnya perlu ditingkatkan. Hal ini karena kesadaran masyarakat untuk memiliki rumah yang cukup ruang untuk menghindari kepadatan permukiman masih lemah. Rendahnya tingkat pendidikan akan mengurangi pentingnya lingkungan permukiman yang sehat (Omole, 2010). Oleh karena itu, diperlukan permukiman yang sehat dalam peningkatan kualitas rumah terutama penghawaanya dalam mendukung obyek wisata Kampung Pelangi. Hal ini dilakukan melalui pengembangan kesadaran pendidikan masyarakat Kampung Pelangi. Pendidikan ini merupakan salah satu indikator yang dilakukan untuk mengembangkan kemampuan, keterampilan, dan sikap untuk menuju pengetahuan dan kehidupan yang lebih baik dari sebelumnya (Sendegeya \& Chiguvare, 2016). Hubungan karakteristik sosial ekonomi masyarakat terhadap perbaikan prasarana permukiman dapat dilihat dalam tabel 4 berikut.

Tabel 4. Nilai Chi-Square Dalam Hubungan Karakteristik Sosial Ekonomi Masyarakat Terhadap Kegiatan Peningkatan KualitasPrasarana Permukiman

\begin{tabular}{|c|c|c|c|c|c|c|c|}
\hline \multirow{2}{*}{\multicolumn{2}{|c|}{ Karakteristik Sosial Ekonomi }} & \multicolumn{2}{|c|}{$\begin{array}{l}\text { Perbaikan } \\
\text { Jalan }\end{array}$} & \multicolumn{2}{|c|}{$\begin{array}{l}\text { Perbaikan } \\
\text { Drainase }\end{array}$} & \multicolumn{2}{|c|}{$\begin{array}{l}\text { Pemeliharaan } \\
\text { Lingkungan }\end{array}$} \\
\hline & & $\mathrm{X}^{2}$ & C & $\mathrm{X}^{2}$ & C & $\mathrm{X}^{2}$ & C \\
\hline & PENDIDIKAN & 0,141 & 0,390 & 0,674 & 0,296 & 0,806 & 0,273 \\
\hline & PEKERJAAN & 0,854 & 0,299 & 0,731 & 0,325 & 0.790 & 0.313 \\
\hline & PENGHASILAN & 0,700 & 0,330 & 0,906 & 0,284 & 0,651 & 0,338 \\
\hline & STATUS RUMAH & 0,877 & 0,211 & 0,784 & 0,234 & 0,028 & 0,403 \\
\hline $\begin{array}{l}\text { KET. } \\
X^{2}\end{array}$ & $=$ Nilai Chi-Square,$C=$ Nila & tingens & Koefien & & & & \\
\hline
\end{tabular}


Dalam tabel 6 tersebut, terdapat hubungan cukup kuat antara status rumah masyarakat terhadap pemeliharaan lingkungan dengan nilai chi-square 0,028 dan nilai kontingen koefisiensi 0.403. Hal ini menyatakan bahwa status rumah masyarakat berperan dalam pemeliharaan lingkungan Kampung Pelangi. Rasa kepemilikan rumah akan menjadi sangat obyektif bagi masyarakat untuk memelihara tempat tinggal dan lingkungannya (Mastura, dkk, 2013). Oleh karena itu, status rumah masyarakat yang sudah menjadi milik pribadi menyebabkan kesadaran akan memperbaiki serta memelihara lingkungan permukiman semakin tinggi.

Penghasilan masyarakat yang rendah menyebabkan mereka hanya mengandalkan bantuan pemerintah dalam perbaikan prasarana. Hal ini menyebabkan masyarakat hanya mampu menyumbangkan tenaganya dengan kesadaran akan rasa memiliki lingkungan hunian melalui status rumahnya yang sudah menjadi pribadi. Hal ini mempengaruhi karakteristik lainnya juga tidak ikut berhubungan dengan peningkatan kualitas prasarana. Oleh karena itu, diperlukan peningkatan pendidikan dan penghasilan masyarakat agar mampu berperan dalam perbaikan lingkungan permukiman dari segi materi, tenaga, dan ide.

\subsection{Peningkatan Kualitas Permukiman Untuk Mendukung Wisata Kampung Pelangi}

Peningkatan Kualitas permukimn yng dilakukan yaitu perbaikan rumah dan prasarana. Perbaikan rumah di Kampung Pelangi, dilakukan oleh masyarakat yang memiliki penghasilan cukup dan memadai untuk melakukan perbaikan. Kegiatan perbaikan yang dilakukan seperti perbaikan atap, penghawaan, dan sanitasi rumah. Dalam perbaikan rumah, terdapat kapasitas masyarakat yang perlu ditingkatkan untuk memiliki kualitas rumah yang baik. Pengembangan kapasitas tersebut yaitu pengembangan kesadaran/pendidikan masyarakat untuk memiliki penghawaan rumah yang baik. Hal ini karena kapasitas pendidikan/pengetahuan masyarakat masih kurang dalam melakukan perbaikan penghawaan rumah untuk meningkatkan kualitas rumahnya di permukiman Kampung Pelangi. Perbaikan kualitas rumah menjadi penting karena akan mendukung keberlanjutan wisata dalam daya tarik/obyek wisata Kampung Pelangi.

Dalam perbaikan/pemeliharaan lingkungan dan prasarana permukiman Kampung Pelangi, paling banyak dilakukan oleh masyarakat yang memiliki status kepemilikan rumah secara pribadi. Hal ini karena status rumah masyarakat akan mempengaruhi masyarakat dalam menjaga lingkungan permukiman. Masyarakat yang memiliki status kepemilikan atas tanah dan rumahnya memungkinkan mereka untuk memiliki kapasitas dalam melakukan perbaikan (Sunarti, Syahbana, \& Manaf, 2014). Oleh karena itu, kesadaran masyarakat dalam memiliki status rumah pribadi perlu ditingkatkan melalui pengembangan kapasitas dan bantuan pemerintah. Pengembangan kapasitas masyarakat untuk status rumahnya menyebabkan kesadaran masyarakat yang tinggi untuk melakukan perbaikan dan pemeliharaan lingkungan akan mendukung keberlanjutan fasilitas, dan aksesibilitas wisata Kampung Pelangi.

Pengembangan kapasitas dimaksudkan sebagai kemampuan untuk membangun hubungan dan nilai yang memungkinkan masyarakat melakukan kerja dalam mencapai tujuan pembangunan (UNEP, 2006). Melalui pengembangan kapasitas masyarakat, akan membuat masyarakat berperan dalam peningkatan kualitas permukiman. Hal ini juga akan mendukung pengembangan wisata Kampung Pelangi. Pengembangan kapasitas ini merupakan pengembangan sumber daya manusia dalam hal proses untuk melengkapi individu dengan pengetahuan, keterampilan, dan akses informasi sehingga memungkinkan mereka melakukan kinerja dengan efektif (Unesco, 2010). Oleh karena itu dengan meningkatnya pengembangan wisata Kampung Pelangi, masyarakat akan mampu mengembangkan kapasitas untuk meningkatkan keterampilan melalui aktivitas wisata seperti mengembangkan wisata kuliner, souvenir, homestay, tourguide, dan retribusi wisata. Pengembangan keterampilan masyarakat ditujukan untuk memiliki pendapatan lebih besar juga dapat mengendalikan hidup serta berkontribusi dalam pembangunan (Noya \& Clarence, 2009). Berdasarkan hal ini, memungkinkan pendapatan yang diperoleh masyarakat Kampung Pelangi akan meningkat melalui aktivitas wisata. Hal ini juga senantiasa membuat masyarakat melakukan dan berkontribusi dalam perbaikan/pemeliharaan kualitas permukiman untuk menunjang wisata Kampung pelangi. 


\section{KESIMPULAN}

Peningkatan kualitas permukiman kumuh dilakukan untuk mengatasi kumuh dan mendukung wisata Kampung Pelangi. Peningkatan ini dilakukan dalam hal perbaikan rumah dan prasarana permukiman. Perbaikan yang paling siginifikan mengalami perubahan adalah atap rumah dan jalan lingkungan. Hasil perbaikan ini mengalami perubahan hanya pada tampak luar saja. Hal ini menyebabkan permukiman kumuh Kampung Pelangi masih ada.

Terdapat hubungan yang terbentuk antara karakteristik masyarakat yang berperan dalam kegiatan peningkatan kualitas permukiman yang dilakukan di Kampung Pelangi. Dalam perbaikan rumah, hubungan yang cukup kuat terdapat pada penghasilan masyarakat terhadap perbaikan bagian atap rumah masyarakat dengan nilai chi-square 0.010 dan nilai kontingen koefisiensi 0.492 . $\mathrm{Hal}$ ini menyebabkan penghasilan masyarakat yang tergolong rendah mampu berperan langsung dalam perbaikan atap rumahnya. Hubungan yang paling lemah terdapat pada pendidikan masyarakat terhadap perbaikan penghawaan rumahnya dengan nilai chi-square 0.046 dan nilai kontingen koefisiensi 0.303 . Hal ini karena pengetahuan dan kapasitas masyarakat masih kurang dalam memperbaiki kualitas penghawaan rumahnya. Dalam perbaikan prasarana permukiman, hubungan cukup kuat terdapat pada status rumah masyarakat terhadap pemeliharaan lingkungan di Kampung Pelangi dengan nilai chi-square 0,028 dan nilai kontingen koefisiensi 0.403 yang berarti cukup kuat. Hal ini karena kesadaran masyarakat untuk memelihara lingkungan prasarana semakin tinggi seiring dengan status rumahnya yang menjadi milik pribadi.

Kondisi rumah ini perlu dilakukan perbaikan lebih lanjut dari segi perbaikan penghawaan rumah melalui pengembangan kapasitas masyarakat. Hal ini karena kondisi penghawaan rumah yang masih dalam kualitas rendah diikuti dengan kesadaran masyarakat yang rendah dalam perbaikannya. Pengembangan kapasitas masyarakat perlu ditingkatkan dalam hal kesadaran untuk memiliki rumah secara pribadi. Hal ini akan menyebabkan masyarakat senantiasa ikut memperbaiki dan memelihara kualitas permukimannya. Kualitas permukiman perlu ditingkatkan agar dapat meningkatkan kualitas hidup masyarakat Kampung Pelangi.

Peningkatan kualitas permukiman ditujukan dalam mendukung wisata, kegiatan perbaikan rumah dilakukan untuk menunjang obyek wisata di Kampung Pelangi. Perbaikan prasarana jalan ditujukan untuk mendukung fasilitas dan aksesibilitas wisata. Hal ini akan memudahkan masyarakat dan wisatawan yang berkunjung di Kampung Pelangi. Peningkatan kualitas permukiman perlu dikembangkan pula untuk mendukung pengembangan akomodasi dan fasilitas layanan wisata yang belum ada. Pengembangan tersebut diantaranya yaitu; pengembangan lahan parkir, homestay, tourguide, dan pengembangan souvenir. Hal ini dilakukan agar memudahkan wisatawan yang berkunjung, meningkatkan wisata, dan dapat meningkatkan pendapatan masyarakat melalui aktivitas wisata.

\section{PERNYATAAN RESMI}

Penelitian ini dilakukan dalam rangka untuk menyelesaikan studi Magister Perencanaan Wilayah dan Kota, Fakultas Teknik, Universitas Diponegoro. Ucapan terima kasih utamanya kepada Allah SWT dan kedua orang tua yang telah memberikan dukungan baik moril dan materil dalam penyelesaian penelitian ini.

\section{REFERENSI}

Changbo, S., \& Jingjing, P. (2011). Construction of Low-carbon Tourist Attractions Based on Low-carbon Economy. Energy Procedia, 5, 759-762. https://doi.org/10.1016/j.egypro.2011.03.133

Ghoomi, H. A., Yazdanfar, S., \& Hosseini, S. (2015). Comparing the Components of Sense of Place in the Traditional and Modern Residential Neighborhoods. Procedia - Social and Behavioral Sciences, 201(February), 275-285. https://doi.org/10.1016/j.sbspro.2015.08.176

Jamaludin, M., \& Abdul, S. (2012). Accessibility in Buildings of Tourist Attraction : A case studies comparison, 35(December 2011), 97-104. https://doi.org/10.1016/j.sbspro.2012.02.067

Javad, S., Poor, A., \& Jusan, M. M. (2012). Exploring Housing Attributes Selection based on Maslow's 
Riyulida, Sunarti/ Jurnal Pembangunan Wilayah dan Kota, Vol 15, No. 2, 2019 , 83-95

Doi: https://doi.org/10.14710/pwk.v15i2.21270

Hierarchy of Needs, 42(July 2010), 311-319. https://doi.org/10.1016/j.sbspro.2012.04.195

Jeuring, J. H. . (2016). Journal of Destination Marketing \& Management Discursive contradictions in regional tourism marketing strategies : The case of Fryslân , The Netherlands. Journal of Destination Marketing \& Management, 5(2), 65-75. https://doi.org/10.1016/j.jdmm.2015.06.002

Khan, A.S. (2014). Education Role In Capacity Building. International Journal of Agricultural Extension, ESci Journals VOL. 6110, Pages 1-7. http:// http://escijournals.net/index.php/IJAE/article/view/640/299.

Kurnianingrum, R. (2016). Kualitas Perumahan di Desa Mranggen Kecamatan Srumbun Kabupaten Magelang. Jurnal Geografi UNNES Volume 13 No. 1 (72 Dari 100), 13(1), 71-78.

Mastura, N., Mohammad, N., Saruwono, M., Said, S. Y., \& Ahmad, W. (2013). A Sense of Place within the Landscape in Cultural Settings. Procedia - Social and Behavioral Sciences, 105, 506-512. https://doi.org/10.1016/j.sbspro.2013.11.054

Moitra, M.K. (1991). Environmental improvement of slums: The Calcutta experience. Building and Environment. vol: 26 (3) pp: 253-257. https://doi.org/10.1016/0360-1323(91)90046-E. ISSN:0360-1323

Muhammad, B. M. dan Sulistyarso H,. (2016). Arahan Penataan Lingkungan Permukiman Kumuh Kecamatan Kenjeran dengan Pendekatan Eco Settlements. Jurnal Teknik ITS Vol. 5, No. 2, (2016) ISSN: 2337-3539

Nisbett, M. (2017). Geoforum Empowering the empowered? Slum tourism and the depoliticization of poverty. Geoforum, 85(July), 37-45. https://doi.org/10.1016/j.geoforum.2017.07.007

Noya, A., \& Clarence, E. (2009). Community capacity building : fostering economic and social resilience. Building, (November), 26-27. Retrieved from http://www.oecd.org/dataoecd/54/10/44681969.pdf

Omole, K. F. (2010). An Assessment of Housing Condition and Socio-Economic Life Styles of Slum Dwellers in Akure, Nigeria. Contemporary Management Research, 6(4), 273-290.

Pantano, E., Priporas, C., \& Stylos, N. (2017). " You will like it!" using open data to predict tourists â $\epsilon^{\mathrm{TM}}$ response to a tourist attraction. Tourism Management, 60, 430-438. https://doi.org/10.1016/j.tourman.2016.12.020

Penataan Kawasan Kampung Pelangi Kelurahan Randusari Kecamatan Semarang Selatan. (2018). Dinas Penataan Ruang Kota Semarang.

Riduwan, dan Sunarto . (2014). Pengantar Statistika untuk Penelitian Pendidikan,Sosial, Ekonomi, Komunikasi, dan Bisnis. Bandung: Alfabeta

Sendegeya, A.-M., \& Chiguvare, Z. (2016). The Role of Academia in Capacity Building for Sustainable Energy Development: The Case of Namibia. Energy Procedia, 93(March), 218-222. https://doi.org/10.1016/j.egypro.2016.07.173

Spirkova, D., Stehlikova, B., \& Zubkova, M. (2017). THE IMPACT OF THE HOUSING QUALITY ON THE SOCIOECONOMIC STANDARD OF THE EU COUNTRIES. Acta Universitatis Agriculturae ET Silviculturae Mendelianae Brunensis, 65(4), 1425-1433.

Suárez, E., Calvo-mora, A., Roldán, J. L., \& Periá, R. (2017). Quantitative research on the EFQM excellence model: A systematic literature review ( $1991-2015)$ 23, 147-156. https://doi.org/10.1016/j.iedeen.2017.05.002

Sunarti, Rahdriawan, M., Dewi, A. P., \& Widiarta, J. R. (2018). Hierarchy model of Tambak Lorok slum area transformation to support marine tourism kampong Hierarchy model of Tambak Lorok slum area transformation to support marine tourism kampong. IOP Conference Series: Earth and Environmental Science PAPER, 202(1). https://doi.org/10.1088/1755-1315/202/1/012061

Sunarti, Syahbana, J. A., \& Manaf, A. (2014). Slum Upgrading Without Displacement at Danukusuman SubDistrict Surakarta City. International Transaction Journal of Engineering, Management, \& Applied Sciences \& Technologies, 5(3), 213-225. https://doi.org/http://TuEngr.com Slum

Uddin, N. (2018). Assessing urban sustainability of slum settlements in Bangladesh: Evidence from Chittagong city. Journal of Urban Management, 7(1), 32-42. https://doi.org/10.1016/j.jum.2018.03.002

UNEP. (2006). Ways to Increase the Effectiveness of Capacity Building for Sustainable Development. Sustainable Development, (May), $1-6$.

Unesco. 2010. Guidebook For Planning Education In Emergencies And Reconstruction . New York: UNESCO an International Institute for Educational Planning.

Yoeti, Oka A. 2003. Tours and Travels Marketing. Jakarta: PT. Pradnya Paramita 